\title{
Reduction of disinfection by-products precursors by nanofiltration process
}

\author{
Yi-Li Lin ${ }^{\mathrm{a}, *}$, Pen-Chi Chiang ${ }^{\mathrm{a}}$, E-E Chang ${ }^{\mathrm{b}}$ \\ ${ }^{a}$ Graduate Institute of Environmental Engineering, National Taiwan University, 71 Chou-Shan Rd., Taipei 106, Taiwan \\ ${ }^{\mathrm{b}}$ Department of Biochemistry, Taipei Medical University, $250 \mathrm{Wu}$-Hshin Street, Taipei 110, Taiwan \\ Received 8 July 2005; received in revised form 8 February 2006; accepted 9 February 2006 \\ Available online 6 March 2006
}

\begin{abstract}
This research is dedicated to determine the rejection ratios of disinfection by-products (DBPs) precursors including resorcinol, phloroglucinol, 3-hydroxybenzoic acid, and tannic acid solution in the presence of calcium by nanofiltration with NF70 membrane. The rejections of these model compounds also were studied at various compositions of a feed solution by changing $\mathrm{pH}$ and concentrations of model compounds. It was found that the model compound rejection and membrane permeability increase with $\mathrm{pH}$ due to the conformational transformation of ionizable molecules and electric interaction between the model compounds and NF70 membrane. The interactions of model compounds with calcium have no significant effect on model compounds retentions. Because of the complexation of calcium with model compounds, calcium rejection rises with the presence of model compounds and with an increase of $\mathrm{pH}$.
\end{abstract}

(C) 2006 Elsevier B.V. All rights reserved.

Keywords: Nanofiltration; Disinfection by-products precursors; Calcium; Drinking water production

\section{Introduction}

Chlorine disinfection is a widely used process for eliminating pathogenic microorganisms from drinking water to prevent water-born diseases. It has been demonstrated that natural organic matter (NOM) in raw water may react with chlorine to form disinfection by-products (DBPs) which are carcinogenic or mutagenic. Owen et al. [1] indicates that a large portion of DBPs was formed from the non-humic fraction of NOM, which is generally more hydrophilic than humic substances and not easily removed by a traditional coagulation process. A previous study indicated that resorcinol structures in aquatic humic materials are the major THM precursor in colored waters [2]. At $\mathrm{pH}$ 8.0, the chlorine reacts with resorcinol and phloroglucinol, to achieve the maximum level of chloroform. The results from Chaidou et al. [3] reveal that the amount of chloroform is affected by the position of chloro or hydroxyl atoms in the phenolic compounds, not the number of these atoms. However, other studies suggested that aliphatic carboxylic acids, hydroxybenzoic acids, phenols and pyrrole derivatives

\footnotetext{
* Corresponding author. Tel.: +886223622510; fax: +886223661642.

E-mail address: f88541104@ntu.edu.tw (Y.-L. Lin).
}

be reactive substrates of organic precursors for THM formation $[4,5]$.

In accordance with the Stage 1 Disinfectants/DBP Rule established by the US Environmental Protection Agency (USEPA) for regulating DBPs [6], the maximum contaminant level of total THMs is limited at $80 \mu \mathrm{g} / \mathrm{L}$. Other more stringent THMs limitation is found in Germany at $10 \mu \mathrm{g} / \mathrm{L}$. The European Union limits chloroform at $30 \mu \mathrm{g} / \mathrm{L}$. To regulate the formation of DBPs, the USEPA Information Collection Rule requires that public water systems conduct treatment studies with membrane separation processes (specifically nanofiltration (NF) or reverse osmosis (RO)) or adsorption processes (granular activated carbon (GAC)) for surface source water with an annual average total organic carbon (TOC) concentration greater than $4.0 \mathrm{mg} / \mathrm{L}$ providing service to more than 100,000 customers, or for ground source water with an annual average TOC concentration greater than $2.0 \mathrm{mg} / \mathrm{L}$ providing service to more than 50,000 customers [7].

Amy et al. [8] indicated that the majority of the THM precursors are present in apparent molecular weight (AMW) fractions less than $1 \mathrm{kDa}$. Jacangelo et al. [9] and Lin et al. [10] reported that because of the high membrane-molecularweight-cutoff (MWCO) of the ultrafiltration (UF) system, only a portion of THM with higher molecular weight (MW) frac- 
tions can be removed, resulting in a high permeate THM yield ( $\mu \mathrm{g}$ THMs/mg C). NF with a relatively lower MWCO of 400-800 Da was effective in controlling the formation of DBPs [11].

Previous researchers have shown that NF membrane technology provides very high rejection of NOM in drinking water treatment [12]. NF may now compete with other NOM treatment technologies such as conventional clarification and GAC adsorption because of simplicity in operation, development of higher flux membrane with lower fouling potentials, and a trend towards lower membrane costs [13]. Some researchers have reported that the membrane process is more cost effective than conventional treatment processes for small systems with treatment capacities of less than $20,000 \mathrm{~m}^{3} / \mathrm{d}$, or $5 \mathrm{mgd}[8,13]$.

Most organic matters responsible for the formation of major DBP precursors in Taiwan source water are small to medium compounds, with a molecular weight of near or less than $1 \mathrm{KDa}$ [14-16]. Only limited research has been done on DBP precursors with different functional groups of small molecular aromatic compounds and their treatability, especially by nanofiltration. Although there were researches conducted in the past to investigate the organic micropollutants in source water, such as endocrine disrupting compounds, pharmaceutically active compounds, pesticides, etc., the knowledge of rejection mechanisms of these compounds is still very limited. For example, Drewes et al. [17], indicated that low MW organic compounds with MWs larger than the MWCOs of two tested membranes (200 and $100 \mathrm{Da}$, respectively) were detected in the RO permeates. However, Najm and Trussel [18] reported that partial rejection of DBPs (THMs, HAAs, and $N$-nitrosodi-methylamine) with MW below the MWCO of tested membranes. Meanwhile, there are hardness problems in some areas in Taiwan, which cannot be ameliorated by conventional treatment processes. Hardness in source water may introduce calcium which may interfere with the removals of DBPs. The fate of NOM in source water may be affected by the following physical chemical processes: binding, transport, and deposition of organic and inorganic pollutants [19]. A thorough understanding of the rejection mechanisms of DBP precursors and performance of NF membrane is necessary to determine the proper type of membrane to be used for the removals of DBPs and the prediction of rejection. Further understanding of the characteristics of DBPs organic precursors with different functional groups also is helpful in determining their treatability by NF membranes.

The objectives of this research are to determine the rejection ratios of four model compounds, i.e., resorcinol, phloroglucinol, 3-hydroxybenzoic acid (chosen to represent small molecular DBP precursors with different functional groups and very high THMFP in surface water) and tannic acid (chosen to represent medium molecular DBP precursors), as well as to investigate the simultaneous removals of calcium and the model compounds by nanofiltration. The experiments were carried out with various $\mathrm{pH}$ values, solute concentrations, and the existence of calcium. Effects of solute type on filtration and the rejection mechanisms of the above target compounds also are studied.

\section{Materials and methods}

\subsection{Membrane and model compounds}

Three model compounds, i.e., phloroglucinol (1,3,5trihroxybenzene), resorcinol (1,3-dihydroxybenzene) and 3hydroxybenzoic acid, with different functional groups of benzene i.e., carboxylic and phenolic groups, were selected to represent small molecular NOM. Tannic acid composing of significant amounts of saccharide and aromatic acid compounds in surface waters was chosen as the fourth model compound in this study to represents a relatively hydrophilic organic with medium molecular weight [20-23]. All model compounds were purchased from Riedel-de Haën. The water samples were prepared using organic-free and de-ionized water (Milli-Q SP). The DOC concentrations for the model compounds were prepared at $2.0,5.0$ and $8.0 \mathrm{mg} / \mathrm{L}$. The $\mathrm{pH}$ levels of the solutions were adjusted within the range between 3 and 10 by the additions of $0.1 \mathrm{M}$ hydrochloric acid and sodium hydroxide. Calcium chloride used as a hardness additive was purchased from Aldrich.

The commercial NF70 membrane produced by Dow-FilmTec was used in this study. Table 1 summarizes the characteristics of NF70 membrane.

\subsection{Filtration tests}

A self-designed, cross-flow mode filtration apparatus with a flat-sheet membrane cell was used for the filtration tests. The experimental apparatus were made of stainless steel to avoid undesirable adsorption of the tested compounds. The effective membrane area was $46.2 \mathrm{~cm}^{2}$. Fig. 1 is a schematic diagram of the filtration module used in this study. All experiments were carried out at a constant temperature $\left(25 \pm 1^{\circ} \mathrm{C}\right)$ and pressure $(0.48 \mathrm{MPa})$ in a recycle mode, which means that both permeate and concentrate were recycled back into the reservoir. The background permeate flux of the membrane was determined initially by measuring the flux of de-ionized water. The average permeate flux for NF70 was found to be $2.5 \mathrm{~mL} / \mathrm{min}\left(9.02 \mathrm{~m}^{3} / \mathrm{m}^{2} \mathrm{~s}\right)$. Control experiments also were carried out to determine the degree of adsorption of target compounds onto the apparatus. The result shows that adsorption onto the apparatus is negligible. In each experiment, a new membrane was used, rinsed with Milli-Q water, and compacted by filtering Milli-Q water overnight before starting a filtration test. Recovery was fixed at $6.3 \%$, and filtration of the feed water containing a model compound was carried

Table 1

Characteristics of the NF70 membrane

\begin{tabular}{ll}
\hline Parameter & Characteristics \\
\hline Manufacture & Dow-FilmTec \\
MWCO $(\mathrm{Da})^{\mathrm{a}}$ & 250 \\
Materials & $0.2 \mu \mathrm{m}$ cross-linked aromatic \\
& polyamide $+0.46 \mu \mathrm{m}$ polysulfone \\
Salt rejection $(\%)^{\mathrm{b}}$ & 98 \\
Charge (neutral $\mathrm{pH})$ & Negative
\end{tabular}

\footnotetext{
a Estimated in this study and Van der Bruggen et al. (1999).
}

b Filtration of $2000 \mathrm{ppm} \mathrm{CaSO}_{4}$ at $0.48 \mathrm{Ma}$ in this study. 


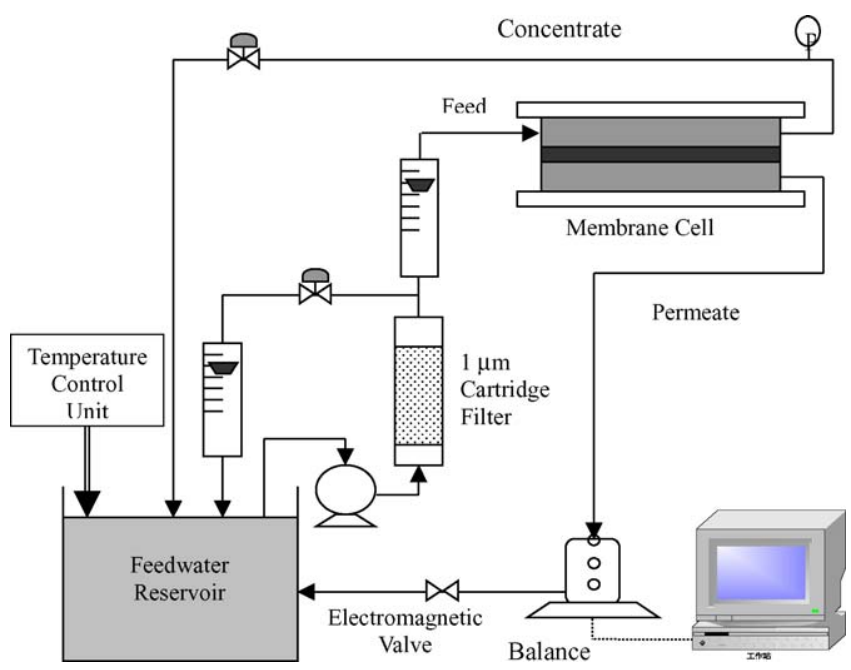

Fig. 1. Schematic diagram of cross-flow nanofiltration experiment setup.

out for $24 \mathrm{~h}$ to avoid over-estimation of rejection [24]. Concentrations of the model compounds in the feed, permeate, and concentrate were determined by measuring the DOC.

\subsection{Analytical methods}

THMs were analyzed after the chlorination experiment. Chlorination was performed with $0.05 \mathrm{M}$ phosphate buffer $(\mathrm{pH} 7.0)$ and sodium hypochlorite at $25^{\circ} \mathrm{C}$. The chlorine residual was maintained at $3-5 \mathrm{mg} / \mathrm{L}$ after 7 days contact time, and the reaction was quenched after $168 \mathrm{~h}$ with a sodium thiosulphate solution. DOC, $\mathrm{pH}$, and THMs were measured for the water samples, followed by the QA/QC programs included in the Standard Methods [25]. THMs were extracted with $n$-pentane, and the extract was then analyzed by GC/ECD (HP 5890-II, USA) with a fused silica capillary column (Restek Mtx-5, 30 m $\times 0.28 \mathrm{~mm}$ ID, and $1.0 \mu \mathrm{m}$ film thickness). Water samples for DOC and $\mathrm{UV}_{254}$ analyses were filtered through a pre-washed $0.45 \mu \mathrm{m}$ filter and then determined by a TOC instrument (O. I. Analytical Model 1010, Texas) and UV spectrophotometer (Cintra 20, GBC
Specific Equipment Pty Ltd., Australia). The concentration of calcium was measured with an atomic absorption spectrophotometer (AAnalyst 800, PerkinElmer instruments, Germany). Duplicate analyses on each sample were performed in accordance with the $\mathrm{QA} / \mathrm{QC}$ requirement, and the average of these two values was reported. If the difference between the two values was greater than $15 \%$, a third analysis was performed, and the average of all three values was reported.

\section{Results and discussion}

\subsection{Effect of solute type on permeate flux at neutral ( $p H 7)$ condition}

Table 2 shows the structures and physical/chemical properties of model compounds. Experiments were conducted with four organic compounds in an aqueous solution at the same transmembrane pressure $(0.48 \mathrm{MPa})$ and cross-flow velocity $(0.30 \mathrm{~m} / \mathrm{s})$. The normalized permeate flux for different model compounds as a function of time are shown in Fig. 2(a). The normalized permeate flux (NPF) is calculated by the following equation:

$\operatorname{NPF}(\%)=\frac{\mathrm{PF}_{\mathrm{f}}}{\mathrm{PF}_{\mathrm{i}}} \times 100$

where $\mathrm{PF}_{\mathrm{f}}$ is the pure water flux with the target compounds after the membrane filtration test, and $\mathrm{PF}_{\mathrm{i}}$ is the pure water flux across a new membrane $\left(\mathrm{m}^{3} /\left(\mathrm{m}^{2} \mathrm{~h}\right)\right)$.

As shown in Fig. 2(a), the fluxes decline rapidly in the presence of model compounds, especially for those compounds with larger MW. The system reaches $90 \%$ of the initial capacity after $20,6.5$ and $1.8 \mathrm{~h}$ of the experiment for phloroglucinol, 3hydroxybenzoic acid and tannic acid, respectively. As expected, the quality of permeate flux is the best for tannic acid (Fig. 2(b)). The concentration of DOC in the permeate increased with time for resorcinol and phloroglucinol, and the rejection ratios for resorcinol and phloroglucinol were measured at 79 and $80 \%$, respectively. The trend of THMFP is similar to that of DOC, i.e., about $98 \%$ of THMFP exerted by tannic acid could be removed,

Table 2

Physical/chemical properties of model compounds (Weast, R.C., 1988; this research)

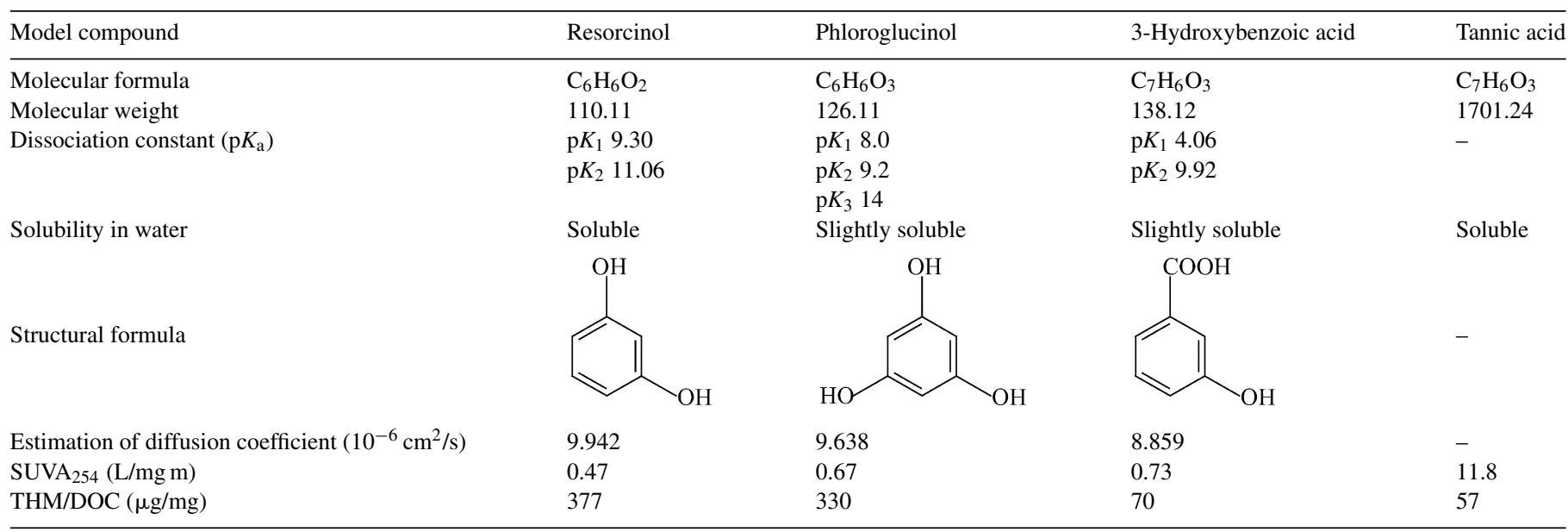



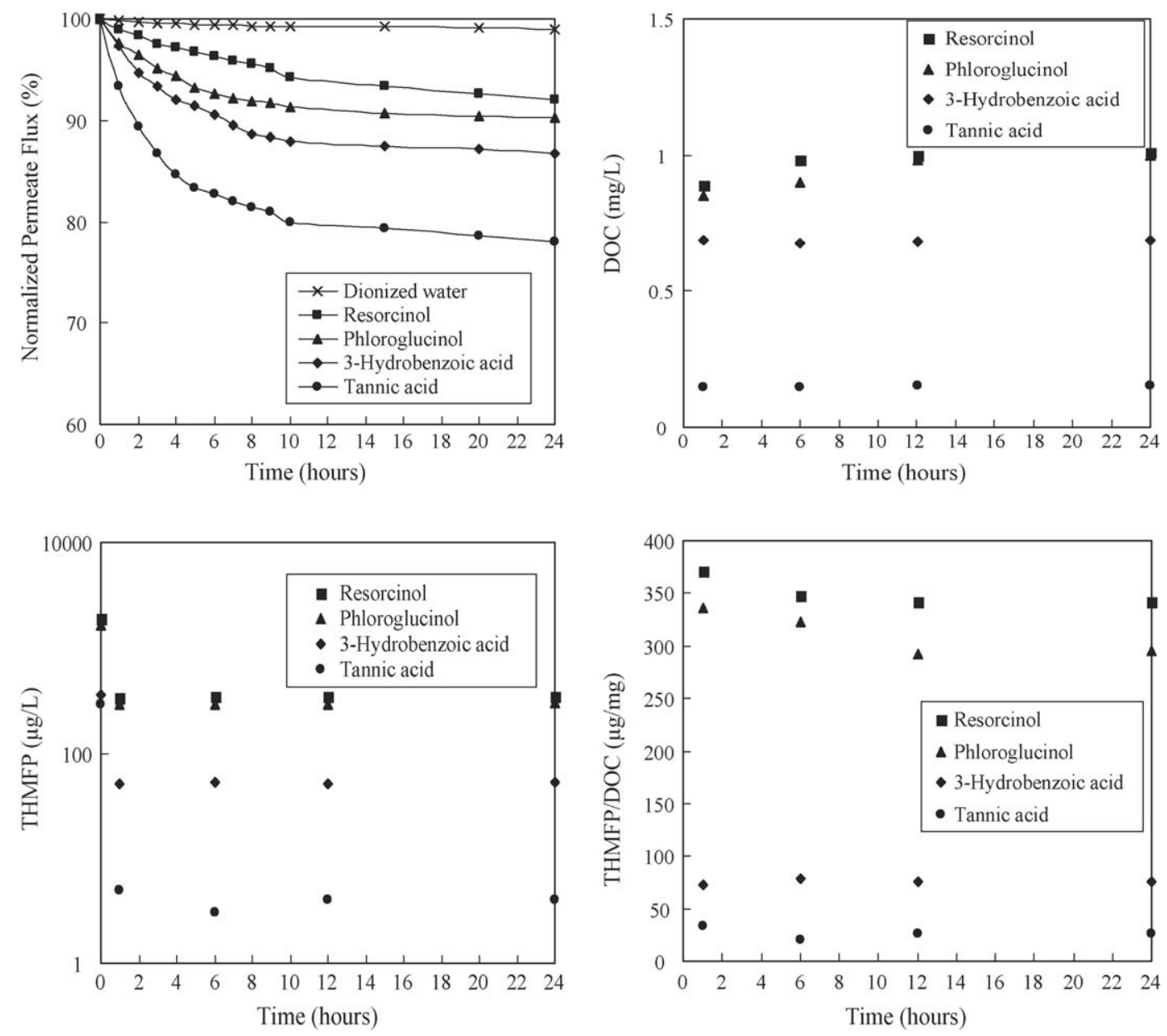

Fig. 2. Permeate quality and flux of model compounds ( $\mathrm{pH} 7$, concentration $=5.0 \mathrm{mg} / \mathrm{L}$ ): (a) flux, (b) DOC, (c) THMFP and (d) THM yield.

whereas only $82 \%$ for resorcinol and phloroglucinol after $24 \mathrm{~h}$ of the experiment (Fig. 2(c)). High THM yields in the permeates for the three small model compounds were observed, although the DOC concentration in the permeate was less then $1.0 \mathrm{mg} / \mathrm{L}$ (Fig. 2(b) and (d)). According to our previous research [26], there is a strong correlation between THMFP and HAAFP for each model compound. Since this research is focused on model compounds not NOMs (natural organic matter), it is representative to present the result of THMFP without HAAFP.

This observation suggests that the NF70 membrane is effective in the removal of DOC for molecules with a broad range of molecular mass. Further treatment processes may be necessary to reduce the levels of small compounds with high THM yields.

Fig. 3 shows the influence of feed concentration on the rejections of model compounds in the absence of calcium at $\mathrm{pH}$ 7.0. Rejections of model compounds were calculated by comparing the concentration of the component in the permeate with the average value of that inside the reservoir (average concentration between the concentrate and the feed) as follows:

$R(\%)=\left(1-\frac{C_{\mathrm{p}}}{C_{\mathrm{f}}}\right) \times 100$

where $R$ is the rejection ratio $(\%), C_{\mathrm{p}}$ the concentration in permeate, and $C_{\mathrm{f}}$ is the average concentration of feed and concentrate.
Fig. 3 shows that the rejection ratio of tannic acid is the highest (89-94\%). This is likely due to its larger molecular size as compared to the pore radius of NF70 membrane. More ionizable functional groups in the chemical structure of tannic acid also may result in the highest rejection ratio. For the other three small

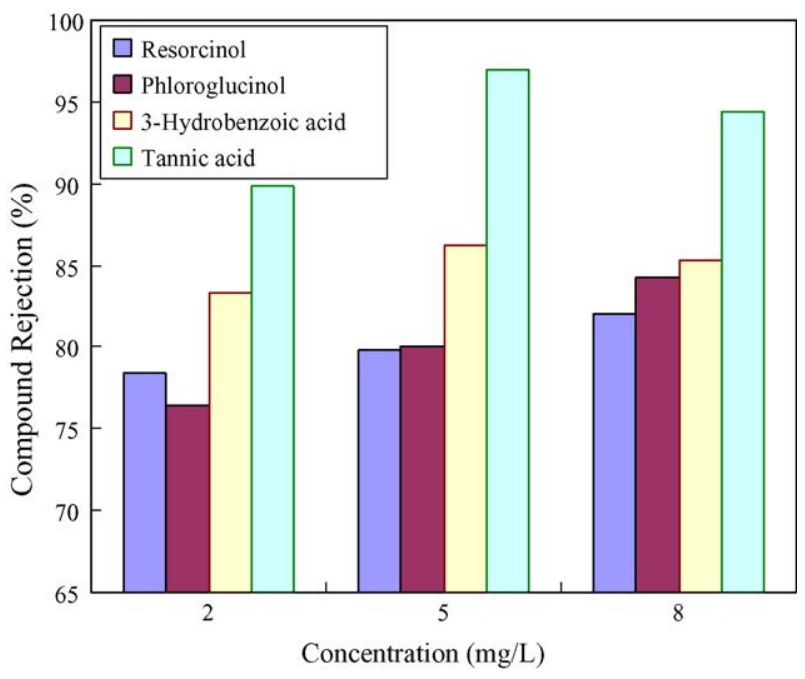

Fig. 3. Influence of feed concentration on rejection of model compounds in the absence of calcium. Initial $\mathrm{pH} 7$. 
model compounds, 3-hydrobenzoic acid has a slightly higher rejection (about 83-86\%) than those of phloroglucinol and resorcinol (having similar rejection about $80 \%$ ). The slightly higher rejection ratio of 3 -hydrobenzonic acid $\left(\mathrm{p} K_{1}=4.06\right)$ is likely due to the electrostatic repulsive interaction between the NF70 membrane (negative charge at neutral $\mathrm{pH}$ ) and the hydrolyzed carboxyl group of 3-hydrobenzonic acid [27]. The rejection ratios of phloroglucinol and resorcinol were lower than that of 3-hydrobenzoic acid although the MWs for all of them are very similar. Phloroglucinol and resorcinol with $\mathrm{p} K_{\mathrm{a}}$ values higher than 7 were not hydrolyzed at $\mathrm{pH} 7$; they possessed no electrical charges and could only be rejected by the sieve action of the NF70 membrane. It was also observed that the trend of the rejection curve with concentration for tannic acid is similar to that of 3-hydrozenzoic acid. As shown in Fig. 3, the rejection ratio increases to the peak when the compound concentration reaches $5 \mathrm{mg} / \mathrm{L}$, and then decreases slightly as the compound concentration continues to rise. For phloroglucinol and resorcinol, the rejection ratio increases as the compound concentration increases.

\subsection{Effect of $p H$ on compound rejection and permeate flux}

As shown in Fig. 4 and mentioned previously, the rejections of all four model compounds increase with an increase of $\mathrm{pH}$. The same phenomenon also was observed by Alpatova et al. [28] that the rejection ratios of humic substances at high $\mathrm{pH}$ were noticeably higher than those of low $\mathrm{pH}$. The increase of rejection ratio at high $\mathrm{pH}$ could be due to the polyelectrolyte character of model compounds and the negatively charged characteristic of NF70 membrane. Similar observation also was reported by other researchers [29-31]. The negative surface charge of the membrane and negative charge density of model compounds increased with increasing $\mathrm{pH}$ values. For tannic acid with medium $\mathrm{MW}$, at $\mathrm{pH}$ values lower than its ionization constant, the molecule is neutral and may form a compact and coiled conformation because of the suppression of dissociation

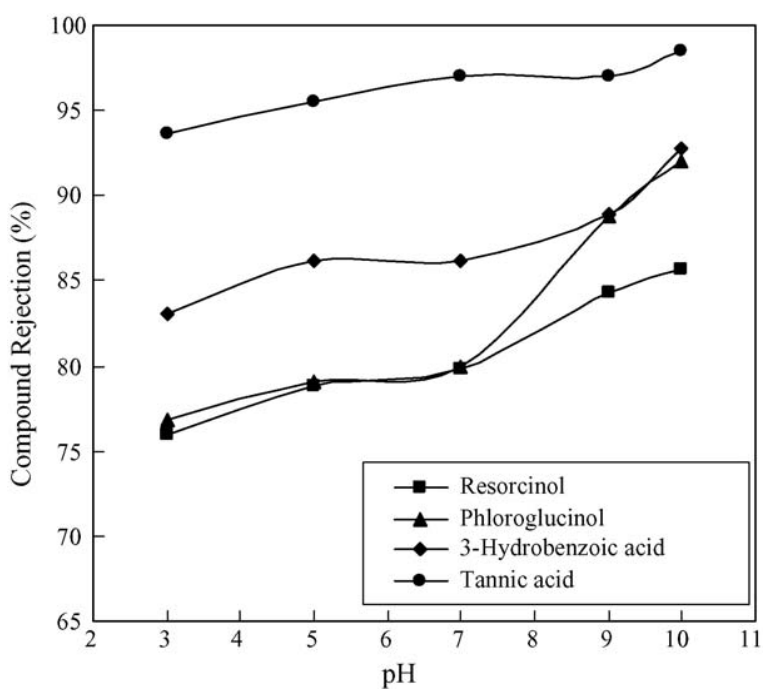

Fig. 4. Influence of the solution $\mathrm{pH}$ on rejection of model compounds in the absence of calcium. Initial concentration: $5 \mathrm{mg} / \mathrm{L}$. of ionogenic groups. Kabsch-Korbutowicz et al. [19] conducted a similar investigation for the humic and fulvic acids and found the same result as this study. The suppression effect leads to a restriction of electrostatic intra-chain repulsion and thus a reduction in the tannic acid molecular size under acidic conditions. Therefore, "sieve effect" became the dominant rejection mechanism at $\mathrm{pH}$ values lower than the ionization constant. However, at $\mathrm{pH}$ values higher than the ionization constant of tannic acid, the molecule unfolds because of the ionization of ionogenic groups leading to electrostatic repulsion between macromolecule segments. The tannic acid molecule now is negatively charged with larger molecular size so that it can be rejected more effectively not only by the "sieve effect" but also the "charge effect" of the NF70 membrane. As a result of these effects, the rejection ratio of tannic acid increased to $98.5 \%$.

For the other model compounds, since the observed $\mathrm{pH}$ values are lower than the ionization constant of each compound, the mechanism for compound rejection is the sieve effect only. For 3-hydrobenzoic acid, it has a slightly higher compound rejection compared to phloroglucinol and resorcinol. At $\mathrm{pH}$ values higher than its $\mathrm{p} K_{1}$ and $\mathrm{p} K_{2}$ values of the 3-hydrobenzoic acid, there is an increase in compound rejection because of the hydrolysis of carboxyl and phenolic groups leading to an electrostatic repulsive interaction with the NF70 membrane [27]. As shown in Fig. 4, the trend of compound rejection versus $\mathrm{pH}$ for 3-hydrobenzoic acid is very similar to that of resorcinol. At $\mathrm{pH}>9.2$, two phenolic functional groups of the phloroglucinol are dissociated. In this case, the charge density and molecular size of phloroglucinol are similar to those of 3-hydrobenzoic acid so that the rejection ratios of the two are similar (about $92 \%$ ).

Fig. 5 shows that the transmembrane flux increases with $\mathrm{pH}$ during nanofiltration of the solutions containing the model compounds. The decrease of membrane fouling with the increase of $\mathrm{pH}$ could be caused by several factors. As mentioned above, at low $\mathrm{pH}$ value, model compounds are neutrally charged, coiled and compacted so that the adsorbed or deposited model compounds on the membrane surface form boundary layers with

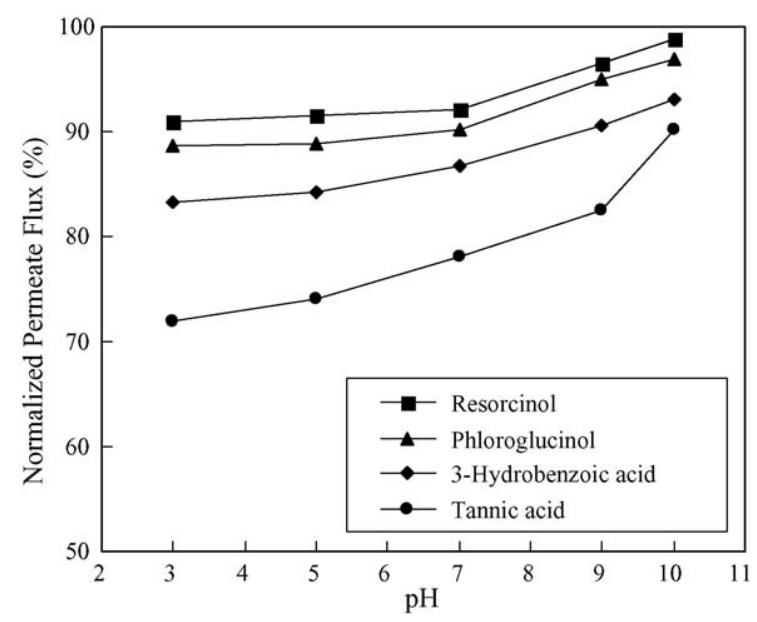

Fig. 5. Influence of the solution $\mathrm{pH}$ on the permeate flux for model compounds in the absence of calcium. Initial concentration: $5 \mathrm{mg} / \mathrm{L}$. 
higher hydraulic resistance resulting in reduction of permeate flux [28]. Under this circumstance, model compounds become less soluble and have a tendency to be adsorbed on hydrophobic materials. NF70 membrane used in this research is a strong hydrophobic membrane made of polyamide materials, and the interaction between model compounds and the NF70 membrane may cause a greater decrease in permeability [19]. This hydrophobic influence on tannic acid with medium MW is stronger than that of the other three small MW model compounds. When the $\mathrm{pH}$ value is higher than 7.0, the dissociation of carboxyl and phenolic functional groups on model compounds increases so that the negative charge density on model compounds rises; meanwhile, the negative charge density on NF70 membrane also increases. Mallubhotla et al. [32] found that phenomena of membrane swelling and charge effects are caused by the $\mathrm{pH}$ variation during membrane filtration. Dissociation of the functional groups on the membrane and the model compounds enhances the electrostatic repulsion between NF70 and model compounds so that the membrane fouling potential is reduced.

\subsection{Effect of calcium on compound rejection and permeate flux}

Rejections of all four model compounds increase with an increase in $\mathrm{pH}$ with or without the presence of calcium ions (Figs. 4 and 6). However, the rejection ratio for each model compound in the presence of calcium ions was slightly lower (Fig. 6) than that in the absence of calcium ions (Fig. 4) at any $\mathrm{pH}$ values. There are several reasons for this phenomenon. First, when calcium ions were added into the solution, the ionic strength in the bulk solution increased and thus influenced the configuration of the model compounds by a contraction of the double-electric layers on model compounds and the membrane surface. Bonner and O'Melia [33] also indicated that humic substances tend to shrink in a solution of high ionic strength, resulting in a reduction of rejection ratio (1991). Secondly, the calcium may form

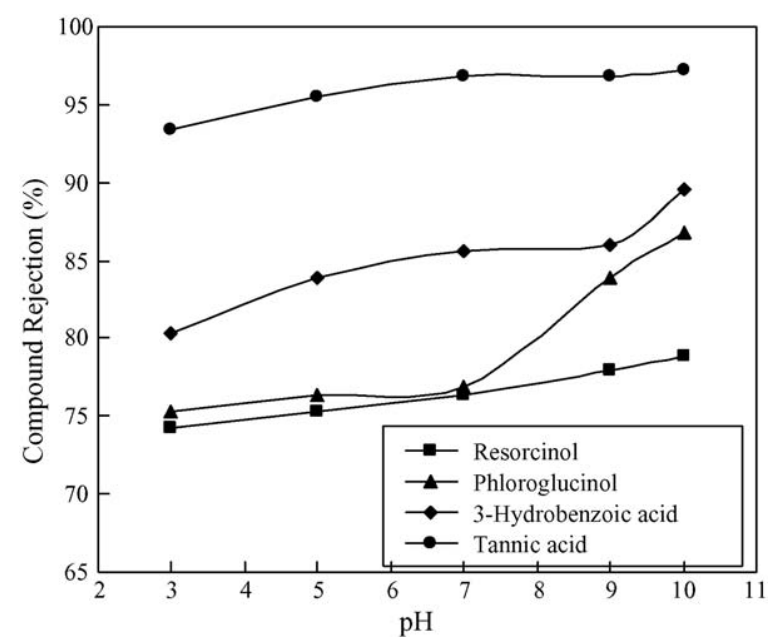

Fig. 6. Influence of the solution $\mathrm{pH}$ and the presence of calcium on rejection of model compounds. Initial concentration: model compounds, $5 \mathrm{mg} / \mathrm{L}$; calcium, $250 \mathrm{mg} / \mathrm{L}\left(\right.$ as $\left.\mathrm{CaCO}_{3}\right)$. complex compounds with model compounds, which reduces the charge repulsion effect between NF70 membrane and model compounds causing the rejection ratio to decrease.

The model compound rejection in the presence of calcium ions at high $\mathrm{pH}$ also was higher than that at low $\mathrm{pH}$ values (Fig. 6). As previously mentioned, the rise of $\mathrm{pH}$ from 3 to 10 in the solution increases the negative surface charges of the model compounds and the NF70 membrane and causes the electrostatic repulsion between each other. However, the increase of negative charge densities could be partially neutralized by the presence of these free positively charged calcium ions which did not form complexes with model compounds. Subsequently, the electrostatic repulsion between the membrane and the model compounds is reduced, and the "sieve effect" becomes a dominant rejection mechanism in the separation of model compounds. Because of those factors, the rejection ratios of model compounds were slightly lower in the presence of calcium ions.

As shown in Fig. 6, the trend of model compound rejections in the presence of calcium ions also is $\mathrm{pH}$ dependent, which implies that the interactions of model compounds with calcium do not have a significant effect on model compound retentions. It can be concluded that the effect of $\mathrm{pH}$ on solute rejections has a greater influence than that of calcium ions. Apparently, the NF70 membrane can separate the selected model compounds successfully in a broad range of $\mathrm{pH}$ in the presence or absence of calcium.

As shown in Fig. 7, the rejection ratio of calcium increases slightly with an increase of $\mathrm{pH}$, but increases significantly in the presence of model compounds. Since metals in strong acid medium are present as free ions, with molecular sizes smaller than the pore size of nanofiltration membranes, they can pass through the membrane freely according to the mechanism of "sieve effect". However, the rejection ratio of calcium by NF70 membrane is still as high as $77-84 \%$ (Fig. 7). The reason for this calcium rejection may be caused by the formation of soluble hydroxo/aqua/complex and hydroxides of calcium and

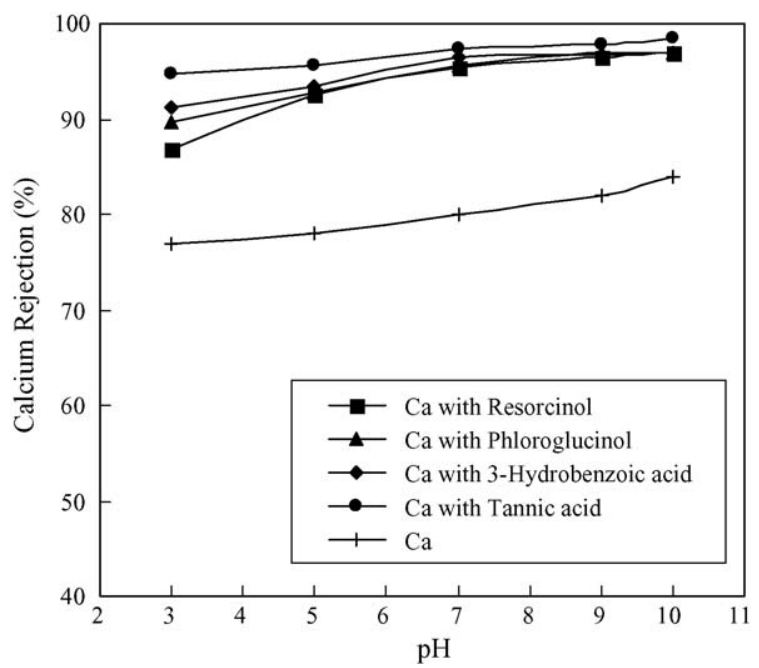

Fig. 7. Influence of the solution $\mathrm{pH}$ and the presence of model compounds on rejection of calcium. Initial concentration: model compounds, $5 \mathrm{mg} / \mathrm{L}$; calcium, $250 \mathrm{mg} / \mathrm{L}\left(\right.$ as $\mathrm{CaCO}_{3}$ ). 


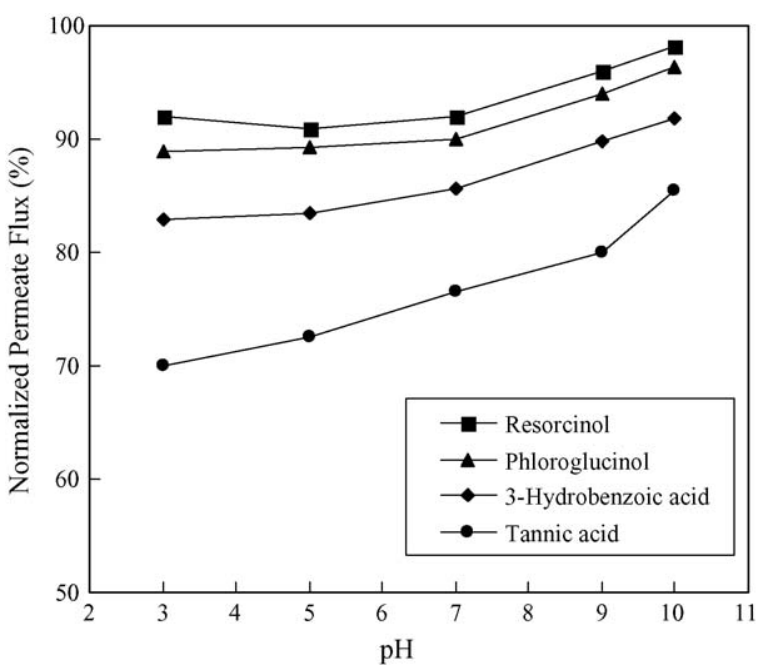

Fig. 8. Influence of the solution $\mathrm{pH}$ on the permeate flux for filtration of model compounds in the presence of calcium. Initial concentration: model compounds, $5 \mathrm{mg} / \mathrm{L}$; calcium, $250 \mathrm{mg} / \mathrm{L}\left(\right.$ as $\left.\mathrm{CaCO}_{3}\right)$.

its precipitation on the membrane surface at high $\mathrm{pH}$ values [28]. While at low pH values, "Donnan effect" is the cause of this calcium rejection [34]. The rejection of calcium ions increased significantly in the presence of model compounds. This increase is caused by the interactions and complexations between model compounds and calcium ions. At low $\mathrm{pH}$ values, the major functional groups of model compounds responsible for metal binding (mainly carboxyl and carbonyl) are undissociated, which inhibits the reactions between model compounds and calcium ions. At the same time, proton competition may happen in this condition and reduce the quantities of bonded calcium ion [28]. As the $\mathrm{pH}$ level increases, the dissociation of functional groups on model compounds causes complexation reaction with calcium ions so that the rejection of calcium ions increases significantly in the presence of model compounds (about 20\% increase). As $\mathrm{pH}$ increases, the negative charge density of model compounds and NF70 membrane increases, respectively, and therefore enhances the electric repulsive force with between NF70 membrane and model compounds. At higher pH values, hydroxo/aqua/complexes of calcium also may be formed. The complexation between model compounds and calcium occurs mainly due to inter-ligand exchange and substitution by carboxyl groups [35]. Therefore, the removal of calcium improves in the presence of model compounds and the increase of $\mathrm{pH}$ at the same time by increasing the quantity of calcium involved in the formation of complexes with model compounds that are rejected by membrane.

Fig. 8 shows that the transmembrane flux increases with $\mathrm{pH}$ in the presence of model compounds containing calcium ions during the nanofiltration process. This influence for tannic acid is more significant than that for the other three model compounds. As mentioned above, at low $\mathrm{pH}$ value, model compounds are coiled and compacted. In the presence of calcium ion, the functional groups undergo further shrinkage so that model compounds and their complex with calcium ions may easily settle on the membrane surface and possibly clog the membrane pores. This process leads to the formation of higher hydraulic resistance layer and thereby reduces the permeate flux.

At higher $\mathrm{pH}$ values, although the presence of calcium ion in the solution causes shrinkage of tannic acid, the dissociation of functional groups are stronger and can be developed in the spatial structure of tannic acid. In this case, the electrostatic interaction between NF70 and tannic acid are intensified and the loose structure of tannic acid still lead to a better permeability at high $\mathrm{pH}$ values in the presence of calcium. For the other three small organic model compounds, the effect of calcium ion on permeate flux is insignificant because of the small molecule size and less functional groups so that the "shrinkage effect" caused by calcium ions is less obvious. The trend of permeate flux for resorcinol, phloroglucinol and 3-hydrobenzoic acid in the presence of calcium ions at different $\mathrm{pH}$ values are very similar to that in the absence of calcium ions.

\section{Conclusions}

From this study, it was concluded that the NF70 membrane is effective in rejection of the chosen model compounds with a wide range of molecular mass. The optimum concentration range of compound rejection can be determined by pretests of the feed water. Although these three small model compounds (resorcinol, phloroglucinol and 3-hydrobenzoic acid) used in this study are very similar in MW, the compound rejection of 3-hrdrobenzoic acid is the highest because of the electrostatic repulsive interaction between NF70 membrane and its ionized functional groups. Model compounds rejection and membrane permeability increase with $\mathrm{pH}$ in the solution due to conformational transformation of ionizable molecules and electric interaction between NF70 membrane and model compounds. The interactions of model compounds with calcium do not significantly affect the model compounds retention. The calcium rejection rises with the presence of model compounds as well as an increase of $\mathrm{pH}$ due to formation of complex between calcium and model compounds.

\section{References}

[1] D.M. Owen, G.L. Amy, Z.K. Chowdhury, R. Paode, G. McCoy, K. Viscosil, NOM characterization and treatability, J. Am. Water Works Assoc. 87 (1995) 46-63.

[2] D.A. Reckhow, P.C. Singer, R.L. Malcolm, Chlorination of humic materials-by-product formation and chemical interpretations, Environ. Sci. Technol. 24 (1990) 1655-1664.

[3] C.I. Chaidou, V.I. Georgakilas, C. Stalikas, M. Saraci, E.S. Lahaniatis, Formation of chloroform by aqueous chlorination of organic compounds, Chemosphere 39 (1999) 587-594.

[4] D.L. Norwood, J.D. Johnson, R.F. Christman, J.R. Hass, M.J. Bobenrieth, Reactions of chlorine with selected aromatic models of aquatic humic material, Environ. Sci. Technol. 14 (1980) 187-190.

[5] G.V. Korshin, C.W. Li, M.M. Benjamin, Monitoring the properties of natural organic matter through UV spectroscopy: a consistent theory, Water Res. 31 (1997) 1787-1795.

[6] USEPA, National primary drinking water regulations: disinfectants and disinfection byproducts; final rule, Federal Register, 63(241) (1998) 69,390-69,476.

[7] S.W. Krasner, G. Amy, Jar-test evaluations of enhanced coagulation, J. Am. Water Works Assoc. 87 (1995) 93-107. 
[8] G.L. Amy, B.C. Alleman, C.B. Cluff, Removal of dissolved organicmatter by nanofiltration, J. Environ. Eng. 116 (1990) 200-205.

[9] J.G. Jacangelo, J. Demarco, D.M. Owen, S.J. Randtke, Selected processes for removing NOM-an overview, J. Am. Water Works Assoc. 87 (1995) 64-77.

[10] C.F. Lin, Y.J. Huang, I.J. Hao, Ultrafiltration processes for removing humic substances: effect of molecular weight fractions and PAC treatment, Water Res. 33 (1999) 1252-1264.

[11] K.M. Agbekodo, B. Legube, S. Dard, Atrazine and simazine removal mechanisms by nanofiltration: influence of natural organic matter concentration, Water Res. 30 (1996) 2535-2542.

[12] J.A. Nilson, F.A. DiGiano, Influence of NOM composition on nanofiltration, J. Am. Water Works Assoc. 88 (1996) 53-66.

[13] M.R. Wiesner, J. Hackney, S. Sethi, J.G. Jacangelo, J.M. Laine, Cost estimates for membrane filtration and conventional treatment, J. Am. Water Works Assoc. 86 (1994) 33-41.

[14] E.E. Chang, P.C. Chaing, Y.W. Ko, W.S. Lan, Characteristics of organic precursors and their relationship with disinfection by-products, Chemosphere 44 (2001) 1231-1236.

[15] P.C. Chiang, E.E. Chang, C.H. Liang, NOM characteristics and treatabilities of ozonation processes, Chemosphere 46 (2002) 929936.

[16] C.W.K. Chow, R. Fabris, M. Drikas, A rapid fractionation technique to characterize natural organic matter for the optimization of water treatment processes, J. Water Supply Res. Technol-Aqua 53 (2004) 8592.

[17] J.E. Drewes, M. Rienhard, P. Fox, Comparing microfiltration-reverse osmosis and soil-aquifer treatment for indirect potable reuse, Water Res. 37 (2003) 3612-3621.

[18] I. Najm, R.R. Trussel, NDMA formation in water and wastewater, J. Am. Water Works Assoc. 93 (2001) 92-99.

[19] M. Kabsch-Korbutowicz, K. Majewska-Nowak, T. Winnicki, Analysis of membrane fouling in the treatment of water solutions containing humic acids and mineral salts, Desalination 126 (1999) 179-185.

[20] I.H. Suffet, M. Malaiyandi, Use of gel permeation chromatography to study water treatment processes, in: Organic Pollutants in Water, Advances in Chemistry 214, ACS, 1989.

[21] J.L. Mallevialle, I.H. Suffet, U.S. Chan, Direct filtration on the Seine river: the importance of chemistry, in: Influence and Removal of Organics in Drinking Water Treatment, Lewis, Chelsea, Mich, 1992.
[22] S.K. Dentel, J.Y. Bottero, K. Khatib, H. Demougeot, J.P. Duguet, C. Anselme, Sorption of tannic acid, phenol, and 2,4,5-trichlorophenol on organoclays, Water Res. 29 (1995) 1273-1280.

[23] G. Newcombe, M. Drikas, S. Assemi, R. Beckett, Influence of characterized natural organic material on activated carbon adsorption. I. Characterization of concentrated reservoir water, Water Res. 31 (1997) 965-972.

[24] K. Kimura, S. Toshima, G. Amy, Y. Watanabe, Rejection of neutral endocrine disrupting compounds (EDCs) and pharmaceutical active compounds (PhACs) by RO membranes, J. Membr. Sci. 245 (2004) 71-78.

[25] APHA, Standard Methods for the Examination of Water and Wastewater, 20th ed., American Public Health Association, Washington, DC, 1998.

[26] E.E. Chang, P.C. Chiang, S.H. Chao, Y.L. Lin, Relationship between chlorine consumption and chlorination by-products formation for model compounds, Chemosphere, in press.

[27] Y.Z. Xu, R.E. Lebrun, Investigation of the solute separation by charged nanofiltration membrane: effect of $\mathrm{pH}$, ionic strength and solute type, J. Membr. Sci. 158 (1999) 93-104.

[28] A. Alpatova, S. Verbych, M. Bryk, R. Nigmatullin, N. Hilal, Ultrafiltration of water containing natural organic matter: heavy metal removing in the hybrid complexation-ultrafiltration process, Sep. Purif. Technol. 40 (2004) 155-162.

[29] A. Braghetta, F.A. Digiano, W.P. Ball, Nanofiltration of natural organic matter: pH and ionic strength effects, J. Environ. Eng. 127 (1997) 628-640.

[30] S. Lee, G. Park, G. Amy, S.K. Hong, S.H. Moon, D.H. Lee, J. Chou, Determination of membrane pore size distribution using the fractional rejection of nonionic and charged macromolecules, J. Membr. Sci. 201 (2002) 191-201.

[31] J. Tanninen, M. Nystrom, Separation of ions in acidic conditions using NF, Desalination 147 (2002) 295-299.

[32] H. Mallubhotla, M. Schmidt, K.H. Lee, G. Belfort, Flux enhancement during Dean vortex tubular membrane nanofiltration: 13. Effects of concentration and solute type, J. Membr. Sci. 153 (1999) 259-269.

[33] A.F. Bonner, C.R. O'Melia, Membrane Technologies in the Water Industry; Proc, AWWA, Orlando, 1991.

[34] A. Seidel, J.J. Waypa, M. Elimelech, Role of charge (Donnan) exclusion in removal of arsenic from water by a negatively charged porous nanofiltration membrane, Environ. Eng. Sci. 18 (2001) 105-113.

[35] A. Martell, The chemistry of metal chelates in plant nutrition, Soil Sci. 84 (1957) 13-26. 